\title{
Cognition Map for the Visually Impaired Individuals in the Special School Type A (Case Study: SMP/SMALB A YPAB Surabaya)
}

\author{
Muhammad Satya Adhitama ${ }^{1 *}$, Rizka Nur Afifah ${ }^{2}$ \\ ${ }^{1,2}$ Department of Architecture, Faculty of Engineering, Universitas Brawijaya, Malang, Indonesia \\ *Corresponding author. Email: sketz29@gmail.com
}

\begin{abstract}
Visually impaired individuals have limitations in vision to capture the information; thus, they have their uniqueness in performing cognition maps. This research is conducted to identify the cognition map by visually impaired individuals in SMP/SMALB A YPAB Surabaya. Based on initial observation, the school has not been designed according to the accessibility standard. Therefore, this research also aims to find out the elements used by visually impaired individuals in understanding their existing environmental conditions. The research uses a descriptive qualitative method by mapping the movement of the visually impaired people and the existing environmental data. The mapping is obtained by a person-centered mapping method with samples from the totally blind, low vision, and a group of blind students that moves without the help of others. Then, analysis is done on the linkage between movement patterns with existing environmental data. As a result, the cognition maps show a difference in the use of physical elements for totally blind, low vision, and group students. The totally blind and the group students primarily used a sense of touch from hands; the second is from the foot. Meanwhile, the low vision students still primarily used the sense of vision, not much with the sense of touch.
\end{abstract}

Keywords: Cognition map, visual impairment, senses

\section{INTRODUCTION}

Visually impaired individuals are divided into two groups, namely, totally blind and low vision, as expressed by Smart [1]. The visual limitations can be a barrier for the blind to carry out their daily activities. When navigating, sighted individuals rely on visual and nonvisual sensory information. Thanks to the integration of the body's multisensory, it is possible to update the body position in the space and to direct ourselves in the environment. In the absence of vision, as in blindness, the navigational ability can be compromised [2,3]. Some studies support this view, demonstrating skill disorders in blind individuals, associated with inferential navigation [4].

In Indonesia, one of the learning media for the blind, which teaches orientation and mobility or basics for the blind to be able to move from one place to another, is through the special school. SMP/SMALB A YPAB Surabaya is the only secondary school (middle and high school) in East Java that specifically facilitates visually impaired students. However, the environment condition has not adequately implemented accessibility standards. Nevertheless, visually impaired students in SMP/SMALB A YPAB Surabaya can still do their daily activities, doing mobility from one place to another so that students are said to have passed the process of cognition map. To facilitate a more accessible map of cognition for visually impaired individuals in the future, it is necessary to know how the cognition map process that already established at this location. This research aims to identify the elements that help the process of environmental cognition for the blinds, which will be developed into a specific design to facilitate the process of cognition map SMP/SMALB A YPAB Surabaya.

Proulx in Robertson [5] demonstrates that a person with reduced vision needs more information and performs more decision-making than a person with normal vision. When collecting information, the blinds use the limits of their vision ability and other senses (tactile, auditory, and smell), temperature, and wind movements. How well this information is delivered to the blind shows how friendly the building is for the visually impaired to perform a cognition map. Thomson in Kurniawan et al. [6] stated that the primary need for total visual impairment is nonvisual clues such as changes in surface texture, embossed letters, games acoustic space, while for the blind with low vision more prioritize in visual clues and can respond to light that is designed in such a way, letters or large objects and codes - color codes

Seeing the limitations of the visually impaired, it takes an individual sensitivity to the environment, so this mobility and orientation become a separate subject to the primary educational institution of the blind. Landmarks and clue, among others, are needed to support the orientation and mobility for the visually impaired [7]. Landmark is a constant and familiar object or stimulation of senses or instructions, that is easy to find and can be reached by the 
visually impaired in which, due to its fixed location, it can be used to distinguish a single location by other locations. A clue is stimulation of either an auditory, tactile, kinesthetic, as well as visual stimuli that reach the functioning senses and can soon be transformed into clues to establish a position or a direction. Different from landmarks, a clue can move or loop and used to keep directions and find specific objects.

\section{RESEARCH METHODS}

\subsection{Research Location}

The research location is in the outdoor area of SMP/SMALB A YPAB Surabaya, a special school type A for visually impaired individuals. The school is located on Jalan Gebang Putih No. 5, Surabaya, Indonesia.

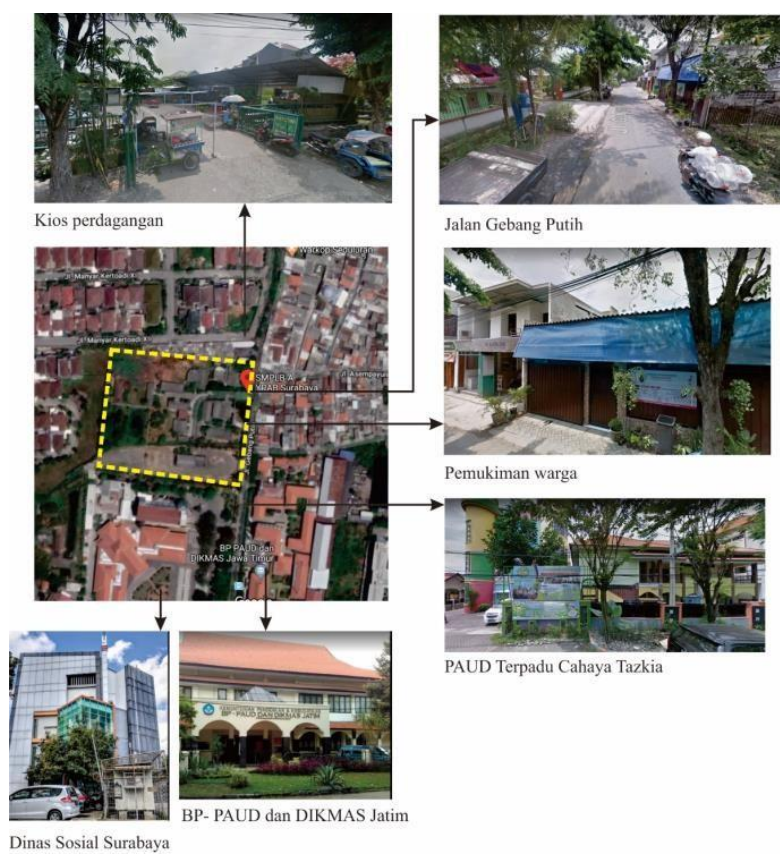

Figure 1 Location and the area surrounding SMP/SMALB A YPAB Surabaya Area

The school consists of 28 students from junior high schools and 9 students from high school. From the observation, the visually impaired students are moving as an individual or in a group. Visually impaired students can be categorized into total blind and low vision. The junior and high school areas are not separated, but rather integrated into one school environment, with the supporting facilities used together.

\subsection{Research Method}

The research used a descriptive qualitative method. According to Sugiyono [8], qualitative research is often referred to as naturalistic, where the research is done in a natural condition and presented by a researcher in a descriptive position so that researchers can describe with more clarity and detail to the reader.

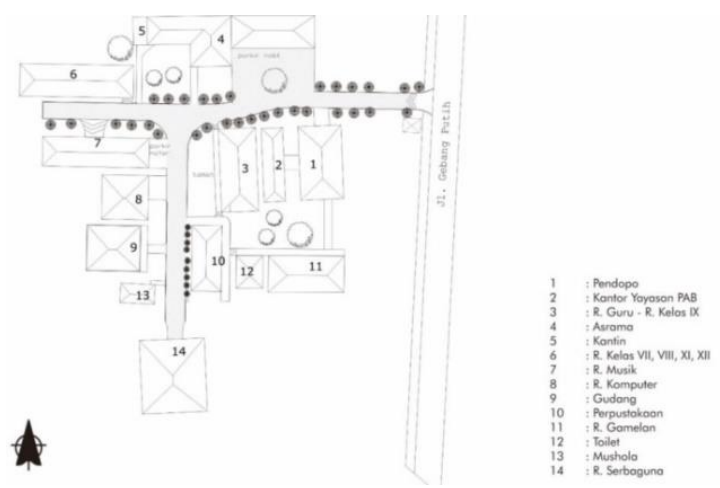

Figure 2. Site plan of SMP/SMALB A YPAB

Surabaya

At the initial observation stage, researchers collect physical setting data on existing conditions. Then observing the movement of students, at which point many cognition maps are performed. The research is conducted at the time of day where many activities in the map of cognition conducted, namely: 1) from Monday to Thursday at the first and second break time at 09.50-12.30, 2) during the Friday prayer time at 11.45-12.30 where students exit the school gate to go to the mosque.

Then movement mapping of the visually impaired students is done by the method of person-centered mapping. Based on Sommer in Haryadi [9], this technique emphasizes on human movements over a period of time. It relates to not just one place/ location but some places/ locations [7].

Based on observations, the movements that often performed by visually impaired students are:

- from classroom VII to canteen

- from classroom $X$ to the mosque

- from classroom IX to Musholla (prayer room)

- from classroom X to dormitory

- from classroom $X$ to teacher room

Samples were taken by the purposive sampling method. Purposive sampling is a data source sampling technique with specific considerations. The sample taken in this study are visually impaired students of SMP/SMALB A YPAB Surabaya who do mobility during the period of research without assistance from other parties.

\section{RESULT AND DISCUSSION}

\subsection{Analysis of the Total Blind Movement}

The analysis is done by establishing a linkage between the total blind movements with the existing environmental conditions. The data of the existing physical settings 
include elements of vegetation, walls, materials, border, road barrier, leveling, and color (see Figure 3 and 4).

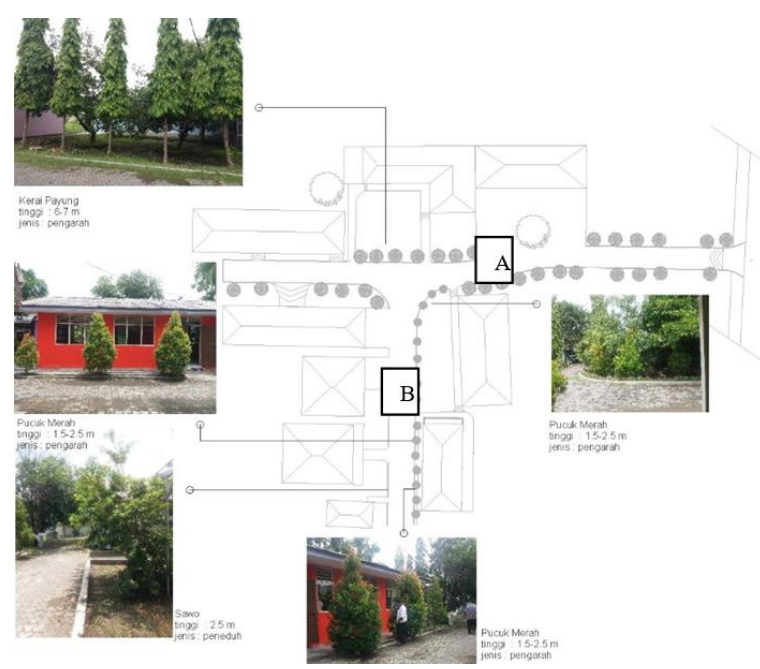

Figure 3 The vegetation in SMP/SMALB YPAB Surabaya

Vegetation element data is presented with a description of vegetation type and vegetation function in the landscape in Figure 3. In this school, there is a pedestrian way with vegetation on both sides. The vegetation in line $\mathrm{A}$ is the type of glodokan tiang (Polyalthia longifolia) with a height of 6-7 $\mathrm{m}$ while on line $\mathrm{B}$ has pucuk merah (Syzygium myrtifolium) with a height of 1.5-2 m.
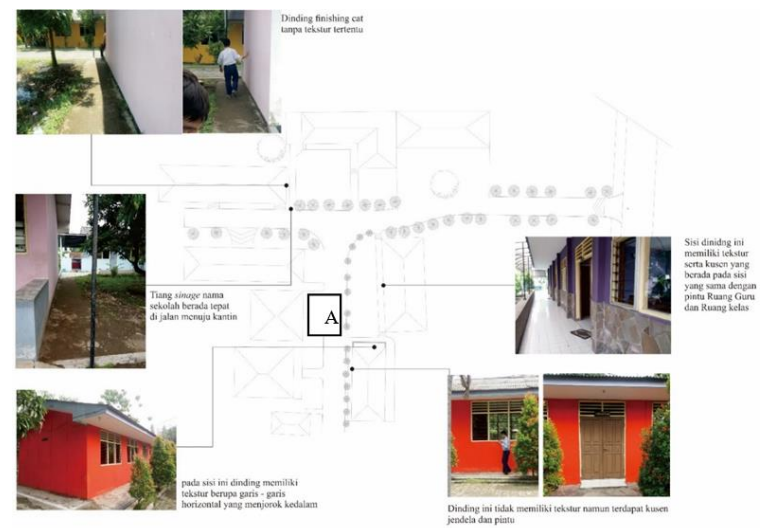

Figure 4 The wall element in SMP/SMALB YPAB Surabaya

Wall element data images are presented in Figure 4. Wall in point $\mathrm{A}$ has a stone texture while the other without recognizable texture.

In addition to existing physical data settings, there are data on the patterns of the visually impaired student's movement, for totally blind, low vision, and a group of students. Researchers recorded the way each category of students moves from one place to another, whether they touch something or slowing down at a certain point. Observations are carried out on every working day for one month. Then, the daily data are overlayed each week.
Furthermore, after one month of research, the weekly data are overlayed to get the final cognition map. Figure 5 shows the process of data overlay for the movement map of totally blind students.

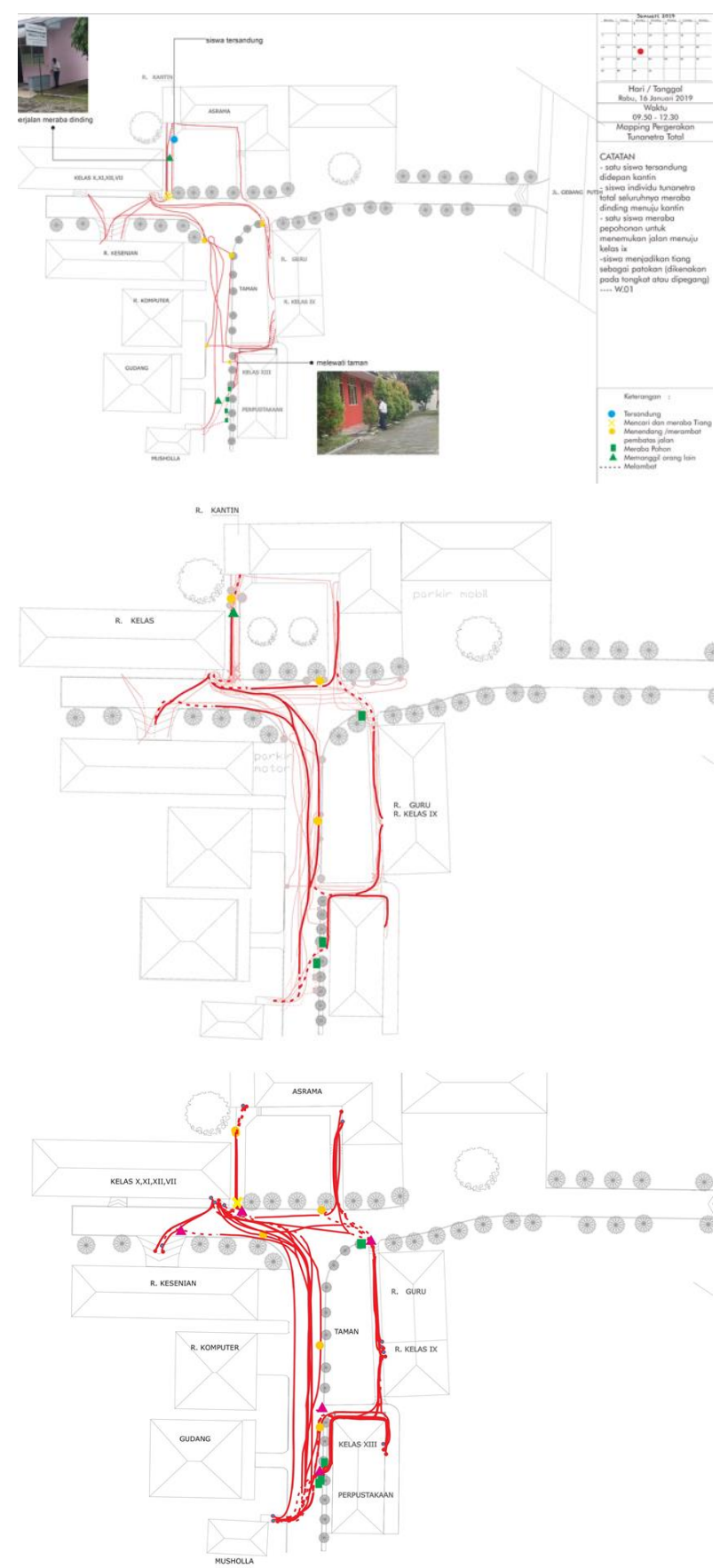

Figure 5 The movement map of totally blind students: the pattern on Wednesday 16 January 2019 (top), the overlay of one-week data in Week 1 (middle), the overlay of one month data (bottom)

After the pattern is established, the next step is analyzing its linkage with the elements in the landscape. For example, at point V4, the totally blind student performs a 
slow movement when turning while touching the vegetation along the line A when going to the Musholla. Then, they were also touching the vegetation when moving from the Musholla to classroom IX. Meanwhile, at point $\mathrm{V} 3$, the total blind has difficulties finding the turning point. However, they did not touch the vegetation as in the point V4, but rather grazing the road barrier with their foot. Based on the physical setting, the vegetation at point $\mathrm{V} 3$ is not quite lush with a small diameter, which makes it unreachable by hand.

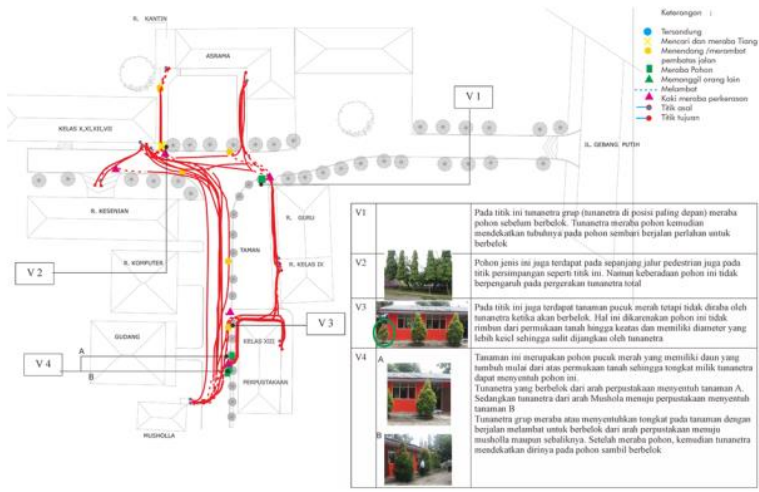

Figure 6 Analysis of the linkage between vegetation elements and the total blind movement pattern

Figure 6 shows the linkage between movement patterns with the wall element. For example, the point of D4 has guiding stones on the floor, but the total blind prefer to walk on the side of the wall while touching the wall, even though the wall does not have a particular texture to redirect. Similarly, at point D5, the total blind walked by touching the window frame on the wall.

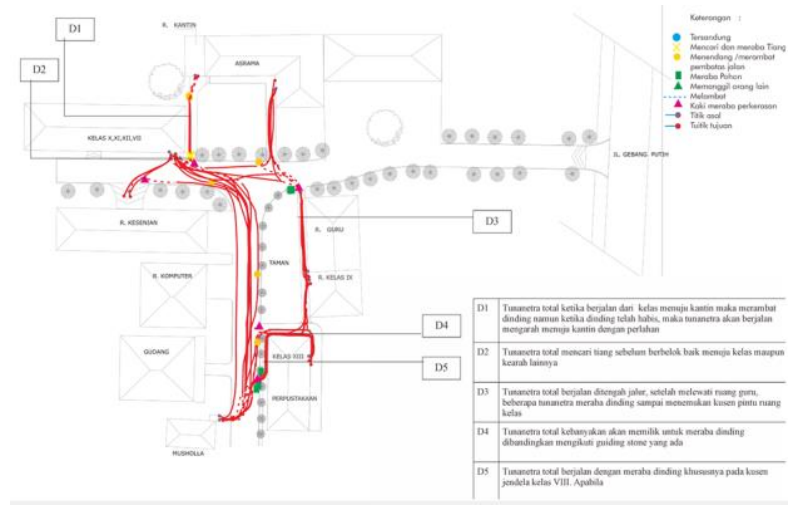

Figure 7 Analysis of the linkage between wall elements and the total blind movement pattern

\subsection{Synthesis of the Total Blind Cognition Maps}

The analysis is then continued with the synthesis of cognition maps. It was done by analyzing which landmark and clue used by the visually impaired students during their movement from one point to another. For example,
Figure 8,9 , and 10 show the cognition map of the total blind moving from classroom IX to the mosque.

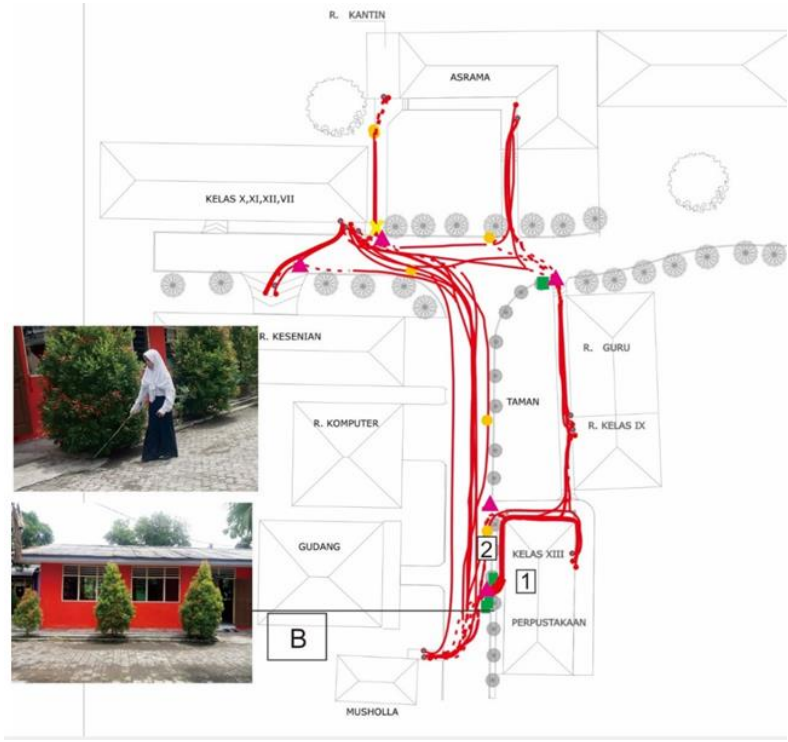

Figure 8 Vegetation as a landmark

Vegetation as a landmark has a fixed location at one point, easy to reach by the blind, is used as a reference point for moving and has distinctive characteristics that can be recognized by the functioning senses.

As illustrated in figure 8 , when heading to the mosque, a total blind is faced with two options, which is line 1 and 2 . The total blind selects line 1 and then grazing their hand or stick to the vegetation when turning to point $B$, and vice versa. The total blind uses vegetation as a landmark. The vegetation at this location is pucuk merah (Syzygium myrtifolium), which leaves spreads from the soil to the top and has sufficient diameter to be grasped by the blind. The total blind can graze their stick at the bottom of the vegetation or directly touching it with the hand.

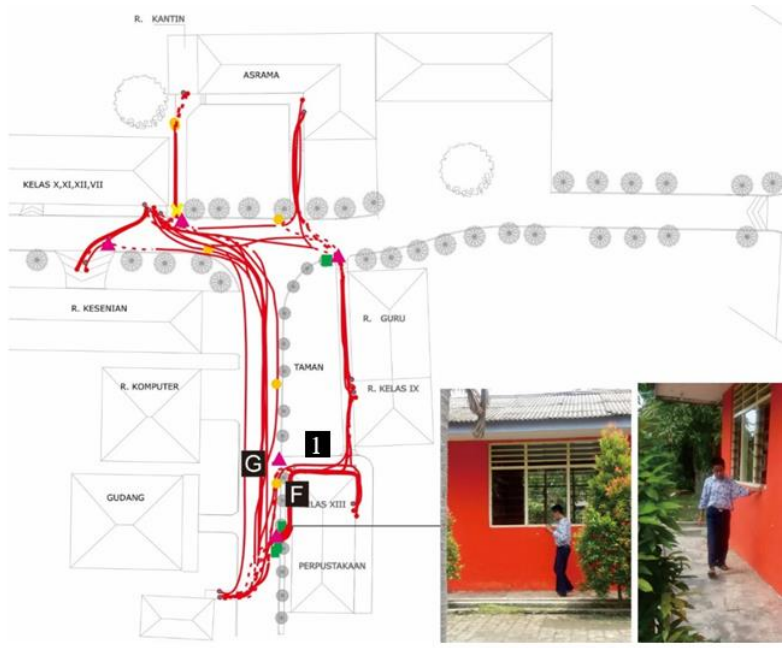

Figure 9 Wall as a clue 
Figure 9 shows that in line 1, the total blinds prefer to walk by touching the wall despite the existing guiding stones on the floor. It seems like they prefer touching the wall than grazing the floor. The clue exists in the form of guiding stones, but in this case, most of the total blinds do not use the guiding stone. It is presumed due to the guiding stone's nonconformity to the standard. Permen PU No 30 Years 2008 requires the guiding tiles' height to be $0.5 \mathrm{~cm}$ and not more than $2 \mathrm{~cm}$. Meanwhile, the existing guiding stones are $3 \mathrm{~cm}$ high.

The total blinds also prefer to pass through the $\mathrm{F}$ line than the $\mathrm{G}$ line when going to the Musholla, or vice versa, even though line $\mathrm{G}$ is $3 \mathrm{~m}$ wide, which is more than the standard of $1,8 \mathrm{~m}$. The total blinds choose to touch the window frame on the wall with their hand to make a turn. This frame is perceived as a guiding texture and becomes a clue.

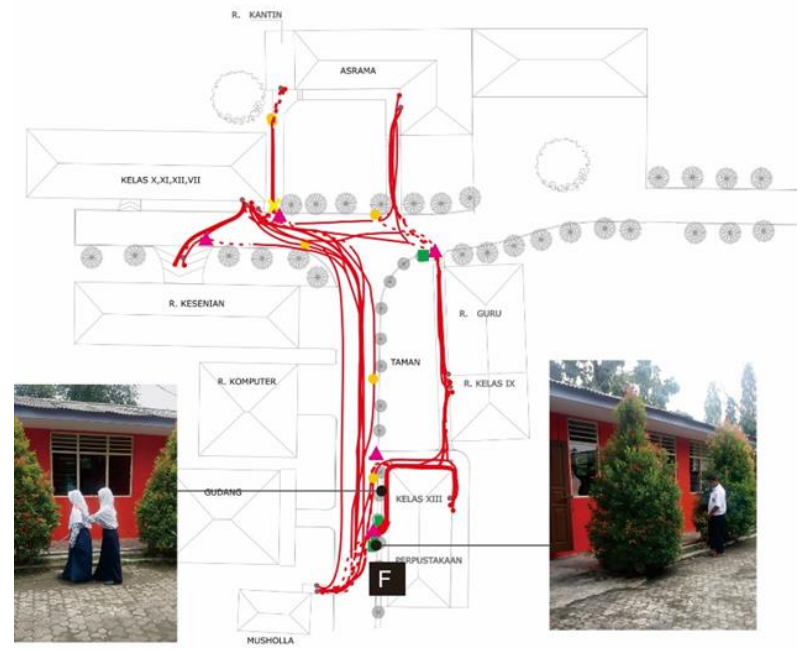

Figure 10 Vegetation as a clue

A clue is dynamic, can be moved or repeated, and can support the orientation, and can help to find specific objects. Figure 10 shows that the vegetation is touched by the blind's hand and stick, but because the vegetation along the path are not arranged tightly so it cannot be touched repeatedly to direct the blind. Thus, the total blinds have difficulties in finding the turning point $\mathrm{F}$ when walking from the mosque to the classroom IX. The total blinds touch the vegetation and then grazing their foot on the road barrier. This road barrier provides orientation by the touch of the foot for the visually impaired. Nevertheless, the existence of vegetation in this path can help facilitate the direction for the blind, the same role as the wall as the tactile guidance.

\section{CONCLUSION}

Based on observations in SMP/SMALB YPAB Surabaya, several elements can help the cognition map process for visually impaired individuals. However, the elements used by the visually impaired as an aid in conducting cognition maps differ from one another.
For the total blind and group students, a widely used cognition map is the element that can be felt or perceived by hand. The walls are used as a clue by the total blinds, even though there are no guiding textures. The vegetation also assists cognition maps for the blinds and plays the same role as the walls. Then, the next important element is the tactile stimuli from the foot, which can be in the form of material, the difference in height, and the existence of the road barrier.

Unlike in the total blind and group of students, the low vision senses are still partially functioned, so they do not use much of tactile senses. For them, the color becomes an important clue.

\section{REFERENCES}

[1] Firdiyansyah, Adif Lazuardy. The visually impaired primary-secondary school through orientation and mobility approach in Malang. Journal of SECTIONS. 4 (1) (2016).

[2] Loomis J. M., Klatzky R. L., Golledge R. G., Cicinelli J. G., Pellegrino J. W., Fry P. A. Nonvisual navigation by blind and sighted: Assessment of path integration ability. J. Exp. Psychol. 122:73 (1993).

[3] Golledge, Reginald \& Klatzky, Roberta \& Loomis, Jack. Cognitive Mapping and Wayfinding by Adults Without Vision, 1996.

[4] Seemungal B. M., Glasauer S., Gresty M. A., Bronstein A. M. Vestibular perception and navigation in the congenitally blind. J. Neurophysiol. 97 (2007) 4341 - 4356. DOI: 10.1152/JN. 01321.200

[5] Robertson, B.S. Map of cognition for Visually Impaired Users of Public Buildings. Access World Magazine. 92 (5) (1998).

[6] Kurniawan H., Maharani RT, \& Hs Atika Rahmawati. Blind People Behaviors to the Architecture of Sekolah Luar Biasa (SLB) MTS

Yaketunis. DIMENSI (Journal of Architecture and Built Environment), 41.2 (2014) 73-78.

[7] Dewantoro, Hajar. Principles of orientation and mobility for the visually impaired, 2016. Online. https://silabus.org/prinsip-orientasi-dan-mobilitas-bagitunanetra/. Accessed November 2018

[8] Sugiyono. Metode Penelitian Kuantitatif, Kualitatif dan R\&D. Bandung: Alfabeta, 2013.

[9] Haryadi B Setiawan, Environmental and behavioral architecture. Yogyakarta: Directorate General of Education, 1995. 